Produto \& Produção, vol 17 n 2, p 1-21, 2016

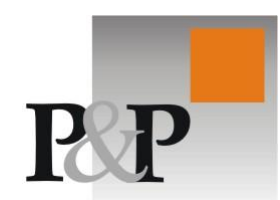

RECEBIDO EM 26/05/2016. ACEITO EM 02/06/2016.

\author{
André Schmidt Lago \\ Faculdade de Engenharia da Pontifícia Universidade Católica do Rio Grande do Sul - \\ FENG/PUCRS \\ andre.lago@acad.pucrs.br
}

Fernando de Oliveira Lemos

Faculdade de Engenharia da Pontifícia Universidade Católica do Rio Grande do Sul FENG/PUCRS

fernando.lemos@pucrs.br

Cesar Luciano K. de Araújo

Faculdade de Engenharia da Pontifícia Universidade Católica do Rio Grande do Sul FENG/PUCRS

cesarlucianok@gmail.com

\title{
Análise e simulação do método de troca rápida de ferramentas em uma empresa gráfica
}

\section{RESUMO}

Um cenário cada vez mais competitivo faz as empresas buscarem ferramentas e métodos para melhorar seus processos produtivos. Conseguir agilidade para atender ao dinamismo do mercado exige flexibilidade por parte da empresa, que pode ser conseguida através da redução do tempo de setup, porém, é importante ter ferramentas que auxiliem a empresa na tomada de decisão. A integração de ferramentas como a Troca Rápida de Ferramentas (TRF) e a Simulação Computacional auxiliam, respectivamente, a melhorar as atividades de setup e avaliar os impactos das mudanças antes de implementá-las. Com o objetivo de propor uma sistemática para avaliar as operações de setup, com o apoio da modelagem e simulação computacional, esse estudo analisou o setup, de uma empresa gráfica de grande porte, propondo melhorias no processo e simulando-as para analisar os resultados obtidos, auxiliando os gestores no processo de tomada de decisão.

Palavras-chave: Simulação Computacional, Troca Rápida de Ferramentas, Setup

\begin{abstract}
A high competitive scenario makes companies seek for tools and methods to improve their production process. Achieving agility in order to attend the market's dynamic, requires flexibility from the company, which can be achieved by reducing the setup time, however it is important to have tools that help the decision making process for the company. The integration of tools, as Single Minute Exchange of Dies (SMED) and Computer Simulation, assist, respectively, to improve setup activities and evaluate the impact of changes before implementing them. With the aim of proposing a systematic
\end{abstract}


approach to evaluate the setup operations, supported by computer modeling and simulation, this study analyzed the setup of a large printing company, proposing improvements in the process and simulating them to analyze the results, supporting the management in the decision making process.

Keywords: Computer Simulation, Single Minute Exchange of Die, Setup

\section{Introdução}

Em um ambiente cada vez mais competitivo, o cliente vem exigindo, gradativamente, produtos de alta qualidade e com um baixo custo (XAVIER et al., 2014). Nesse ambiente, as empresas conseguem se manter competitivas, se atenderem às necessidades dos consumidores de forma cada vez mais rápida e flexível (SOARES et al., 2011). Para isso, as empresas contam com tecnologias métodos e ferramentas já consagrados, que auxiliam na busca pelo aumento da capacidade produtiva, pela otimização dos processos produtivos, pela redução de custos e pelo aumento da qualidade (MIRANDA et al., 2010).

Uma das iniciativas mais conhecidas globalmente é a Produção Enxuta, oriunda do Sistema Toyota de Produção (STP). O foco dessa abordagem é a redução de custo, eliminando atividades que não agregam valor ao produto. Para isso, o modelo propõe a utilização de técnicas para melhorar o desempenho da empresa, como, por exemplo (ABDULMALEK; RAJGOPAL, 2007): sistema de produção puxado, manufatura celular, minimização dos estoques, Manutenção Produtiva Total (TPM) e Troca Rápida de Ferramentas (TRF).

A TRF é um conjunto de técnicas que auxilia na redução do tempo de setup (SHINGO, 2000). Um tempo de operação de setup menor permite uma resposta mais rápida às variações de mercado, menor nível de estoque, ganho em qualidade, redução de custo de fabricação e diminuição do seu lead time (tempo de atravessamento) (SATOLO; CALARGE, 2008; ELIAS; NETO; DYNA, 2008; RANGEL et al., 2012). Vários estudos validam os benefícios de implementação da TRF, como, por exemplo, Monteiro et al. (2005), Pontes et al. (2007), Maia et al. (2008) e Oliveira (2008), que concluíram, após a aplicação da TRF, que houve um aumento de produtividade e disponibilidade de máquina nos processos produtivos analisados.

Contudo, as empresas se deparam com a escassez de recursos para realizar investimentos em seus processos, a fim de torná-los mais eficientes. Assim, a tomada de decisão precisa ser objetiva, para não haver um equívoco na implementação de algo que não atenderá ao resultado esperado (HARREL et al., 2002). Tendo isso em vista, a simulação computacional tem sido usada para criar cenários a um baixo custo e visualizar os impactos de uma mudança, sem, de fato, alterar o processo produtivo da empresa (OLIVEIRA, 2008). De acordo com estudo realizado por Bateman et al. (2013), empresas que fazem uso da modelagem e simulação, conseguem adquirir vantagens competitivas em relação aos concorrentes, por se tratar de uma ferramenta que adiciona criatividade ao processo de resolução de problemas e incorpora a variabilidade do sistema.

A simulação é uma ferramenta estratégica que, a partir de um modelo matemático, auxilia na análise dos resultados, diminuindo os riscos na tomada de decisão e permitindo a avaliação da viabilidade econômica de um projeto (CARLETO, 2006). Assim, a simulação computacional auxilia na tomada de decisão de possíveis melhorias no processo produtivo da empresa, como por exemplo na identificação e ajustes dos gargalos produtivos, na identificação de deficiências do processo, originário da má utilização dos recursos disponíveis ou tempos de processo muito longos (WILLIAMS; ÇELIK, 1998).

Alguns autores obtiveram sucesso ao utilizar a simulação computacional para avaliar o impacto da utilização da metodologia da TRF no setup estudado. Oliveira (2013), utilizou a simulação para analisar as consequências da TRF em um processo de extrusão de polímeros. Carnovali et al. (2012), utilizaram a simulação computacional, em uma empresa que produz utensílios domésticos através da injeção de polímeros termoplásticos, para avaliar a aplicação da TRF, a fim de reduzir o tempo de setup.

Considerando os aspectos abordados, o objetivo esse trabalho é propor uma sistemática para avaliar as operações de setup de uma empresa gráfica, integrada a um processo de modelagem e simulação computacional. Para isso foi realizado um levantamento de técnicas de TRF e modelagem computacional, para identificar as técnicas que podem ser utilizadas nas operações de setup da 
empresa estudada. $\mathrm{O}$ estudo propõe a utilização da simulação computacional, como ferramenta de análise de alterações nas operações de setup, a partir da aplicação da metodologia da TRF, com o objetivo de reduzir o tempo de setup e, consequentemente, aumentar a disponibilidade do processo analisado.

A sistemática proposta foi aplicada em uma linha de produção específica de uma empresa gráfica de grande porte. A linha de produção em estudo, apresenta um alto tempo de setup e, consequentemente, possui um índice de disponibilidade inferior ao esperado pela empresa, afetando a capacidade produtiva. Desde sua implementação, essa linha de produção já teve seu tempo de setup reduzido em cerca de $50 \%$, porém a empresa identificou, através do benchmarking, entre as outras unidades da empresa, que esse tempo pode ser reduzido ainda mais.

O estudo avaliou, principalmente, os seguintes indicadores: tempo de setup, disponibilidade da linha de produção e ociosidade dos funcionários. Questões como qualificação dos trabalhadores envolvidos e impactos econômicos não foram abordados. Vale ressaltar que o presente estudo utilizou os conceitos da TRF e não abordou a ferramenta em sua plenitude, a qual objetiva realizar o setup em menos de 9 minutos e 59 segundos. Além disso, a análise proposta foi aplicada apenas a uma linha de produção específica, responsável pela impressão de 4 produtos diferentes. Por fim, por pedido da empresa, os dados coletados foram ajustados com um fator $(k)$, com o propósito de manter o sigilo das informações.

A partir da aplicação da sistemática proposta, foi possível gerar um modelo computacional válido e propor cenários com melhorias no processo de setup, como a transferência de tarefas de setup interno para externo, a gestão do gargalo e a melhor utilização dos funcionários que atuam no processo de setup.

\section{Sistema Toyota de Produção e a Troca Rápida de Ferramentas}

Um dos pilares do STP é o JIT (Just in Time), um sistema que busca gerenciar um processo para que ele tenha apenas o necessário, na quantidade necessária, no tempo certo, sem o acúmulo de peças (SHINGO, 2000). Entre os elementos do JIT, necessários para o sucesso do sistema, está a TRF (MARTINS; LAUGENI, 2002). A TRF tem como objetivo reduzir as perdas associadas à operação de setup, para conseguir realizar a operação de forma mais rápida e simplificada (FOGLIATTO; FAGUNDES, 2003).

Há muitos estudos que os autores utilizaram a TRF a fim de minimizar o tempo de setup, como Fagundes (2002), que aplicou a ferramenta, em uma empresa do ramo moveleiro, e conseguiu reduzir o tempo total de setup de 660:53 minutos para 119:23 minutos e proporcionar um aumento de produção de 8.864 unidades. Brandi e Giacaglia (2012) aplicaram a TRF em uma indústria gráfica de embalagens, gerando um ganho de $45 \%$ de disponibilidade da máquina e redução dos tempos de setup interno em $44 \%$ e setup externo em $50 \%$.

Para a aplicação da TRF, Shingo (2000) propõe quatro estágios conceituais. No estágio inicial (preliminar), não há distinção entre o setup interno (que ocorre enquanto a máquina não está funcionando) e o setup externo (operações que podem ser realizadas enquanto a máquina está em funcionamento). Nesta etapa, o objetivo é realizar um estudo de tempos e movimentos de cada fase do setup. Na etapa seguinte, denominada de Estágio 1, os tempos são organizados e classificados, separando-os em interno e externo. No Estágio 2, busca-se tornar as operações consideradas internas em externas, através da padronização das ferramentas, por exemplo. Por fim, no Estágio 3, ocorre a busca de melhorias em tudo que envolve a máquina, como implementação de operações em paralelo e redução ou eliminação de ajustes (SHINGO, 2000).

Shingo (2000) também propôs oito técnicas, relacionadas aos estágios, para auxiliar na redução do tempo de setup. São elas: (i) separar as atividades de setup interno e externo (Estágio 1); (ii) converter o setup interno em externo (Estágio 2); (iii) padronizar a função dos elementos de setup (Estágio 2); (iv) utilizar fixadores funcionais ou eliminar os fixadores (Estágio 3); (v) utilizar dispositivos intermediários que evitem ajustes durante o setup interno (Estágio 3); (vi) empregar operações paralelas (Estágio 3); (vii) eliminar ajustes através da padronização (Estágio 1); e (viii) mecanizar (Estágio 3). 
Além de Shingo, outros autores propuseram sistemáticas para implementar a TRF. Monden (1983), por exemplo, propõe quatro estratégias e seis técnicas para a implementação. As quatro estratégias definidas por Monden (1983) são: (i) distinção do setup interno e externo; (ii) eliminação de ajustes e busca de padronização das ferramentas; (iii) busca pela eliminação do processo de troca de ferramentas através da intercambiabilidade entre peças; e (iv) a produção simultânea de várias peças. A diferença entre as técnicas é que Monden (1983) propõe que a conversão do tempo de setup interno em externo seja realizado junto com a padronização, enfatizando que a padronização das ferramentas deve acontecer somente se impactar na redução da troca de ferramenta, devido ao custo do investimento.

Black (1998) propõe sete passos para a implementação da TRF. O primeiro acontece através do estudo de tempos e movimentos das operações de setup, procurando eliminar os movimentos que não são necessários. Os passos 2 (separar tempos de setup interno do externo), 3 (converter o setup interno em externo) e 4 (reduzir ou eliminar o setup interno), correspondem aos estágios 1 e 2 propostos por Shingo (2000). Por fim, os passos 5 (aplicar análise de métodos), 6 (padronizar o setup) e 7 (eliminar os ajustes e buscar a mecanização) se equivalem ao Estágio 3 de Shingo (2000). Destacase que no passo 5, Black (1998) sugere a forte participação dos operadores na análise do setup interno. Além disso, nesse passo, busca-se a multifuncionalidade do operador, através de treinamento e qualificação do mesmo.

A Figura 1 apresenta uma comparação entre as etapas de implementação da TRF, a partir das metodologias desenvolvidas pelos autores citados anteriormente. Shingo (2000) direciona seus estudos para uma aplicação mais operacional das atividades de setup. Já Monden (1983), se preocupou em buscar a excelência no setup, propondo uma análise da conversão do setup interno em externo junto com a padronização das ferramentas e, quando possível, produzir diversas peças ao mesmo tempo. Por fim, Black (1998) destaca a preocupação com o funcionário, ou seja, ele entende que é necessário treinar e qualificar o operador, a fim de otimizar o setup. Por fim, a Figura 2 apresenta os efeitos esperados com a implementação da TRF.

\begin{tabular}{|l|c|c|c|}
\hline \multicolumn{1}{|c|}{ Etapas para Implementação da TRF } & Shingo (2000) & Monden (1983) & Black (1998) \\
\hline Estudar as operações de setup & $\mathrm{X}$ & $\mathrm{X}$ & $\mathrm{X}$ \\
\hline $\begin{array}{l}\text { Separar os tempos de setup } \text { interno do } \\
\text { externo }\end{array}$ & $\mathrm{X}$ & $\mathrm{X}$ & $\mathrm{X}$ \\
\hline Converter o setup interno em externo & $\mathrm{X}$ & $\mathrm{X}$ & $\mathrm{X}$ \\
\cline { 1 - 2 } $\begin{array}{l}\text { Padronizar a função dos elementos de } \\
\text { setup }\end{array}$ & $\mathrm{X}$ & $\mathrm{X}$ \\
\hline $\begin{array}{l}\text { Utilizar fixadores funcionais ou } \\
\text { eliminar os fixadores }\end{array}$ & $\mathrm{X}$ & $\mathrm{X}$ & \\
\hline $\begin{array}{l}\text { Utilizar dispositivos intermediários que } \\
\text { evitem ajustes durante o setup } \text { interno }\end{array}$ & $\mathrm{X}$ & $\mathrm{X}$ & $\mathrm{X}$ \\
\hline Empregar operações paralelas & $\mathrm{X}$ & & $\mathrm{X}$ \\
\hline Eliminar ajustes & & $\mathrm{X}$ & \\
\hline Mecanizar & & $\mathrm{X}$ & \\
\hline $\begin{array}{l}\text { Analisar os métodos, treinamento } \mathrm{e} \\
\text { qualificação do operador }\end{array}$ & $\mathrm{X}$ & \\
\hline Padronizar as ferramentas & & $\mathrm{X}$ & \\
\hline Intercambiabilizar as peças & & & \\
\hline Produzir simultâneamente várias peças & & & \\
\hline
\end{tabular}

Figura 1 - Comparativo entre as etapas propostas para a implementação da TRF Fonte: Elaborado pelos autores 


\begin{tabular}{|l|l|}
\hline \multicolumn{1}{|c|}{ Características } & Efeito Esperado \\
\hline Setup interno & Redução \\
\hline Tempo de setup & Redução \\
\hline Disponibilidade da linha de produção & Aumento \\
\hline Capacidade produtiva & Aumento \\
\hline Mix de produção & Aumento \\
\hline Nível de estoque & Redução \\
\hline Qualidade & Aumento \\
\hline Custo de fabricação & Redução \\
\hline Lead Time & Redução \\
\hline
\end{tabular}

Figura 2 - Efeitos esperados com a implementação da TRF

Fonte: Adaptado de Shingo (2000)

\section{Simulação Computacional}

A simulação computacional recria o processo, gerando uma história artificial, a partir da qual, observações são feitas com a intenção de elaborar inferências sobre as características operacionais do sistema representado (BANKS, 1998). A simulação computacional busca usar um modelo para desenvolver conclusões que forneçam conhecimentos sobre como um processo se comportará com a implementação de mudanças (MCHANEY, 1991; PEREIRA,2000).

A elaboração de modelos ajustados à realidade, onde é possível testar diferentes cenários sem comprometer os recursos disponíveis, a habilidade de simular sistemas complexos, que não seriam bem descritos por modelos matemáticos, a possibilidade de analisar longos períodos de tempo de uma operação em um curto espaço de tempo e a redução dos custos de experimentação, são algumas das vantagens de se utilizar a simulação computacional (LAW; KELTON, 2000; BATEMAN et al., 2013).

A Simulação Computacional é implementada por metodologias que variam de autor para autor. Chwif (1999), propõe um ciclo de vida para o modelo de simulação, por entender que não há uma sequência de etapas lineares, mas, sim, várias interações, retornos e novas alimentações no processo. O ciclo proposto pelo autor, contempla três fases: a concepção, a implementação e a análise.

Durante a fase de concepção, deve haver um entendimento do sistema a ser simulado e a definição dos objetivos que devem ser alcançados. Nessa fase, também ocorre a coleta de dados que irão alimentar a simulação. Por fim, através de técnicas de representação, o sistema deve ser demonstrado em um modelo conceitual, para que outras pessoas possam compreendê-lo (CHWIF, 1999).

A implementação ocorre na segunda fase. Nela, conforme Chwif (1999), o modelo conceitual definido é transformado em modelo computacional, que deve ser verificado e validado em relação ao modelo conceitual. Para isso, alguns resultados devem ser gerados no modelo computacional, a fim de confrontá-los com o que acontece na realidade.

Na terceira fase, ocorre a análise dos resultados das simulações e realização dos experimentos. Recomendações para auxiliar na tomada de decisão são realizadas nesta etapa. Se necessário, o modelo pode ser alterado, reiniciando o ciclo (CHWIF, 1999).

Harrel et al. (2002) apresentam uma proposta semelhante à de Chwif (1999). A Figura 3 estabelece um comparativo entre as etapas propostas pelos dois autores. Além disso, foi adicionada a metodologia proposta por Law e Kelton (2000), para exemplificar a semelhança com a metodologia de Harrel et al. (2002). Nota-se que Harrel et al. (2002) incorporam a etapa de Implementação em seu modelo, mostrando a preocupação dos autores em, além de analisar alternativas para o processo em estudo, implementar as alternativas de melhoria. Além disso, os autores consideram que a criação de um modelo abstrato está inserida no modelo conceitual, ocorrendo, assim, em uma única etapa. Por 
outro lado, Chwif (1999) tem o foco em uma metodologia de simulação mais robusta, com a proposta de um modelo cíclico de simulação.

\begin{tabular}{|c|c|c|c|}
\hline Características & Chwif (1999) & Harrel et al. (2002) & Law e Kelton (2000) \\
\hline Proposta de modelo cíclico & $\mathrm{X}$ & & \\
\hline Proposta de modelo linear & & $\mathrm{X}$ & $\mathrm{X}$ \\
\hline Formular o Problema & $\mathrm{X}$ & $\mathrm{X}$ & \multirow{2}{*}{$\mathrm{X}$} \\
\hline Definir os objetivos & $\mathrm{X}$ & $\mathrm{X}$ & \\
\hline Criar o Modelo abstrato & $\mathrm{X}$ & \multirow{2}{*}{$\mathrm{X}$} & \multirow{3}{*}{$\mathrm{x}$} \\
\hline Criar o Modelo conceitual & $\mathrm{X}$ & & \\
\hline Coletar os dados & $\mathrm{X}$ & $\mathrm{X}$ & \\
\hline Validar Modelo Conceitual & $\mathrm{X}$ & $\mathrm{X}$ & $\mathrm{X}$ \\
\hline Criar Modelo computacional & $\mathrm{X}$ & $\mathrm{X}$ & $\mathrm{X}$ \\
\hline Realizar Verificação & $\mathrm{X}$ & $\mathrm{X}$ & $\mathrm{X}$ \\
\hline Realizar Validação & $\mathrm{X}$ & $\mathrm{X}$ & $\mathrm{X}$ \\
\hline Realizar Experimentos & $\mathrm{X}$ & $\mathrm{X}$ & $\mathrm{X}$ \\
\hline Analisar & $\mathrm{X}$ & $\mathrm{X}$ & $\mathrm{X}$ \\
\hline Apresentar os resultados & $\mathrm{X}$ & $\mathrm{X}$ & $\mathrm{X}$ \\
\hline Implementar melhorias & & $\mathrm{X}$ & $\mathrm{X}$ \\
\hline
\end{tabular}

Figura 3 - Descrição das etapas de simulação proposta por Harrel et al. (2002) Fonte: Elaborado pelos autores

\section{Método de Trabalho}

O método proposto é uma adaptação das etapas para desenvolvimento de um projeto de simulação propostas por Harrel et al. (2002) e por Chwif (1999). Além disso, as etapas de TRF definidas por Shingo (2000) também foram incorporadas no método de trabalho. Sendo assim, a sistemática proposta é composta por 3 fases: Concepção, Implementação e Análise (Figura 4).

A Fase de Concepção contempla as seguintes etapas: (i) Formulação do problema; (ii) Coleta de dados e análise dos processos de setup (realização do Estágio preliminar e Estágio 1 da TRF); (iii) Construção do modelo conceitual e (iv) Validação do modelo conceitual. A segunda Fase engloba três etapas, a saber: (i) Construção do modelo computacional; (ii) Verificação do modelo computacional e (iii) Validação do modelo computacional. A Etapa de Análise está estruturada nas atividade de: (i) Definição do(s) experimento(s); (ii) Realização da simulação do(s) experimento(s); (iii) Análise dos resultados; e (iv) Conclusões e recomendações.

A Fase 1 inicia com a formulação do problema a ser estudado, que é a etapa mais importante do processo, já que ela irá guiar as próximas atividades e a definição do escopo. Um escopo bem definido permite um entendimento claro sobre os objetivos a serem alcançados durante o trabalho, bem como as delimitações do modelo (BANKS, 1998).

$\mathrm{Na}$ etapa seguinte é realizada a coleta de dados, tais como: identificação das operações que envolvem o setup e seus respectivos tempos de operação. Depois dos dados coletados (Estágio preliminar da TRF) e organizados (Estágio 1 da TRF), ocorre a definição do modelo conceitual, a partir das características do processo estudado, como a relação dos recursos e indicadores de desempenho (SOARES et al., 2011).

Com essas etapas concluídas, é necessário que o modelo conceitual seja validado, encerrando, assim, a Fase 1 da metodologia proposta. A validação do modelo conceitual confirma que o mesmo contempla as operações do sistema real (HARREL et al., 2002) e ajuda a evitar reprogramações significativas nas etapas seguintes (LAW; KELTON, 2000).

A Fase 2, de Implementação, tem início na construção do modelo computacional, que pode ocorrer através da linguagem de programação (linguagem $\mathrm{C}$, por exemplo) ou através do uso de um software de simulação (Arena, AutoMod ou ProModel, por exemplo). 


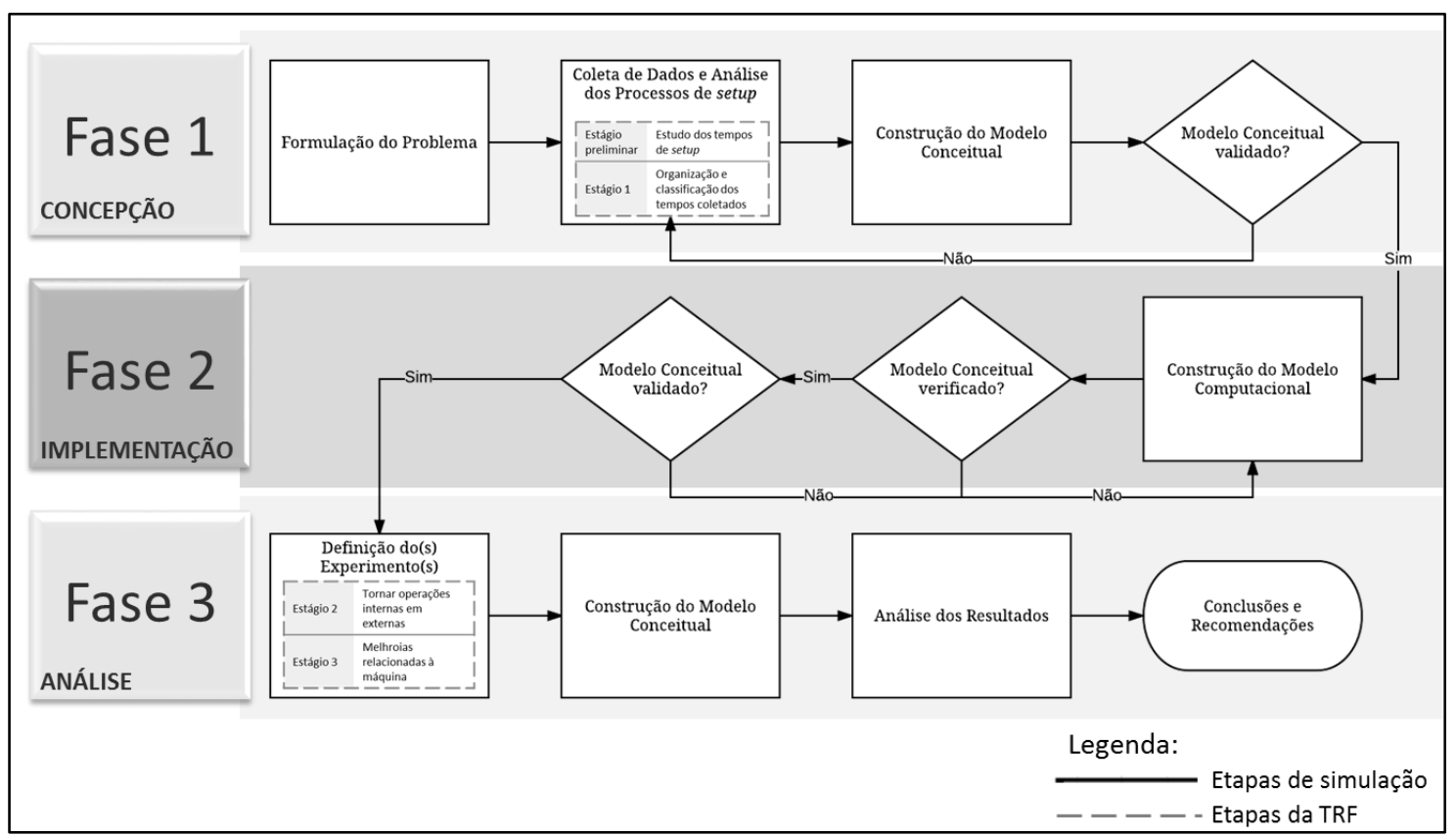

Figura 4 - Método de trabalho proposto

Fonte: Adaptado de Chwif (1999), Harrel et al. (2002) e Shingo (2000)

Assim como o modelo conceitual, o modelo computacional também precisa ser validado, porém, antes disso acontecer, ele deve ser verificado. Uma das maneiras de verificar o modelo é através da animação do modelo no software de simulação, para verificar a movimentação dos recursos e trabalhadores. Além disso, a utilização de contadores pode ser exibida durante a animação, garantindo que as variáveis estão respondendo adequadamente (HARREL et al., 2002). Com essa etapa assegurada, o modelo precisa ser validado. Isso pode ser feito comparando os resultados obtidos na simulação com os resultados, já conhecidos, do sistema real ou com resultados de um outro modelo, previamente validado. Outra possibilidade é entrar com dados históricos e verificar se as saídas do modelo são semelhantes às obtidas com as saídas históricas (SARGENT, 2011).

Com o modelo computacional validado, encerra-se a Fase 2. Na fase de Análise são definidas as mudanças que serão feitas no modelo computacional, a fim de analisar diferentes cenários e comparar diferentes alternativas. Essas mudanças serão embasadas nos Estágios 2 e 3, descritos por Shingo (2000).

Com as definições das mudanças estabelecidas, é realizada a simulação de fato. Para cada cenário simulado são gerados resultados diferentes de tempo de setup e utilização dos funcionários, que devem ser analisados com o objetivo de identificar a melhor proposta a ser implementada.

\section{Aplicação Prática}

Essa seção aborda o estudo de caso em uma empresa de grande porte, líder mundial no fornecimento de soluções de embalagem, presente em 43 países e com mais de 27 mil funcionários. $\mathrm{O}$ método de trabalho foi aplicado em uma unidade fornecedora embalagens.

\subsection{Etapa 1: Concepção}

Conforme descrito no Método de Trabalho, a primeira etapa consistiu na formulação do problema, coleta de dados, construção e validação do modelo conceitual.

\subsubsection{Formulação do Problema}

A linha de produção do presente estudo foi escolhida pela gerência da empresa devido ao elevado tempo de setup que ela apresenta, gerando um índice de disponibilidade menor do que o 
esperado. A linha é responsável pela impressão dos principais produtos da empresa, sendo estratégica para o negócio da empresa, necessitando, assim, ter uma maior disponibilidade para produção.

Em média, a linha de produção fica 34,54\% do tempo indisponível, sendo que, em média, $16 \%$ desse tempo é devido ao setup realizado nela. Estes valores médios foram obtidos a partir dos dados de indisponibilidade e setup da linha de produção (Figura 5). É possível observar uma relação direta entre a diminuição do setup e a indisponibilidade da linha de produção.

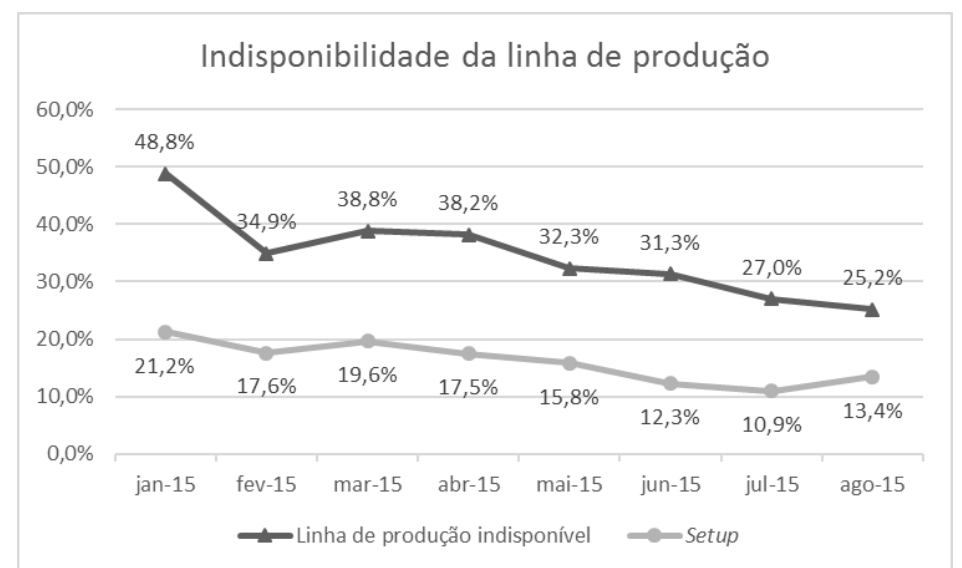

Figura 5 - Dados de indisponibilidade da linha de produção e setup Fonte: Elaborado pelos autores

Com isso, o problema consiste em minimizar o tempo de operação de setup através da metodologia da TRF para verificar as consequências que as mudanças propostas causam na linha de produção. Além disso, foram definidos como indicadores para análise: tempo de setup, disponibilidade da linha de produção e utilização dos funcionários.

\subsubsection{Coleta de dados e Análise dos Processos de Setup}

Nessa etapa foram coletados os dados de entrada para modelar o processo de setup. Inicialmente, foi necessário entender o processo de produção, cada operação envolvida no setup, para, posteriormente, coletar os tempos de operação.

A linha de produção estudada imprime os cartões da embalagem dos cigarros (que em outro processo se tornam os estojos dos cigarros) em um processo de rotogravura. O processo de impressão por rotogravura é um processo de impressão de baixo relevo, em que os cilindros de impressão (unidades impressoras), após terem sido banhados de tinta, transferem a mesma para o papel. Antes de serem instalados na linha de produção, os cilindros são preparados com uma gravação específica e com um banho de cromo. Durante o processo de impressão, uma lâmina metálica raspa a superfície do cilindro com tinta, antes que o papel entre em contato com o cilindro, fazendo com que apenas a imagem gravada no cilindro seja impressa no papel. O processo ainda conta com um rolo de pressão um cilindro que pressiona o papel contra a unidade impressora, garantindo a transferência de tinta - e com uma estufa, para secagem e remoção do solvente de tinta.

A Figura 6 representa a linha de produção estudada. A "bobina" é o local onde fica armazenada a bobina de papel a ser impressa. A área de "impressão" é composta por 9 estruturas, em que cada uma delas possui um rolo de pressão, uma unidade de impressão, um tinteiro e uma estufa. $\mathrm{O}$ "relevo" é uma matriz semelhante à unidade impressora e garante o baixo relevo da impressão. O "vinco" garante a posição que o papel será dobrado quando o cartão impresso for montado, enquanto que a matriz de "corte" secciona o papel no tamanho e formato que se deseja. 


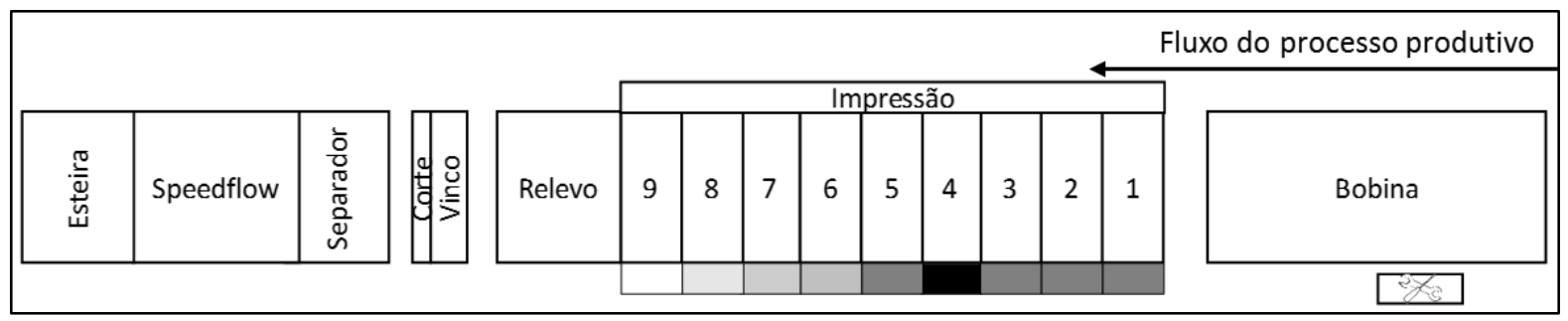

Figura 6 - Representação da linha de produção estudada Fonte: Elaborado pelos autores

O "separador", literalmente, separa o cartão cortado, fazendo a transferência do produto para o "speedflow", que auxilia na coleta dos produtos acabados. No início, ele possui um sistema composto por 4 a 6 rolos (varia dependendo do formato que está sendo impresso), que auxiliam na acomodação dos cartões (no presente trabalho, será chamado de "speedflow - rolinhos"), enquanto que no final, há um outro sistema formado por 3 pequenas paredes (no trabalho será chamado de "speedflow batedores"), que auxiliam a agrupar os cartões em pilhas. Essas pilhas são disponibilizadas na "esteira", onde um operador as dispõe na embalagem final.

Na linha de produção estudada são realizados dois tipos de setup: (i) troca de formato e (ii) troca de gravura no mesmo formato (Figura 7). A equipe em estudo é composta por um técnico gráfico, um mecânico e quatro operadores. Eles são responsáveis por atuar na bobina, impressão, separador e speedflow, enquanto que as outras operações, realizadas na linha de produção, são realizadas por equipes de apoio, que não fazem parte do escopo do presente estudo. Por ser mais complexo, o estudo focou nas operações que ocorrem no setup com troca de formato.

\begin{tabular}{|l|c|c|}
\hline \multicolumn{1}{|c|}{ Operação/Atividade } & Troca de formato & Troca de gravura no mesmo formato \\
\hline Garantir que toda a equipe esteja com os com EPIs & $\mathrm{X}$ & $\mathrm{X}$ \\
\hline Finalizar a burocracia da última produção & $\mathrm{X}$ & $\mathrm{X}$ \\
\hline Preparar o "Registrom" para o próximo trabalho & $\mathrm{X}$ & $\mathrm{X}$ \\
\hline Solicitar a nova bobina de papel & $\mathrm{X}$ & \\
\hline Posicionar a nova bobina & $\mathrm{X}$ & \\
\hline Retirar o papel em processo & $\mathrm{X}$ & $\mathrm{X}$ \\
\hline Trocar os tinteiros & $\mathrm{X}$ & \\
\hline Trocar o(s) cinlindro(s) de impressão & $\mathrm{X}$ (até 9 cilindros) & $\mathrm{X}$ (no mínimo l cilindro) \\
\hline Trocar os rolos de pressão & $\mathrm{X}$ & \\
\hline Ajustar o separador & $\mathrm{X}$ & \\
\hline Ajustar o Speedflow - "rolinhos" & $\mathrm{X}$ & \\
\hline Ajustar o Speedflow - "batedores" & $\mathrm{X}$ & \\
\hline Alinhar o papel da nova bobina & $\mathrm{X}$ & \\
\hline Iniciar a primeira puxada do papel & $\mathrm{X}$ & $\mathrm{X}$ \\
\hline Realizar o acerto de registro de cores & $\mathrm{X}$ & $\mathrm{X}$ \\
\hline Realizar o ajuste fino no separador e speedflow ("rolinhos" e "batedores") & & \\
\hline
\end{tabular}

Figura 7 - Diferenças entre os setups realizados na linha de produção estudada Fonte: Elaborado pelos autores

Os dados coletados foram obtidos através de um estudo de tempos e movimentos, no qual foi realizado o acompanhamento das operações que envolvem o setup estudado. A partir da equação (1), calcula-se o tamanho de amostra necessária para o estudo realizado (WALPOLE et al., 2012). Nesse momento, ainda não há distinção entre setup interno e externo.

$$
N=\left(\frac{z_{\alpha / 2} \cdot s}{a \cdot x}\right)^{2}
$$

Sendo, $N=$ tamanho da amostra; $\mathrm{Z}_{\alpha / 2}=$ valor crítico para o grau de confiança desejado; $s=$ desvio padrão amostral; $a=$ a precisão final desejada; e $x=$ média amostral. 
Para cada operação foram feitas, inicialmente, 10 observações para o cálculo do tamanho da amostra, considerando um nível de confiança de $95 \%\left(Z_{\alpha / 2}=1,96\right)$ e precisão igual a $10 \%$. A Figura 8 exemplifica uma coleta de tempos realizada para a operação de troca de 1 rolo de pressão. A coleta de dados teve o acompanhamento da gerência, que validou os tempos obtidos.

\begin{tabular}{|l|c|c|c|c|c|c|c|c|c|c||}
\hline \multicolumn{1}{|c|}{$n$} & 1 & 2 & 3 & 4 & 5 & 6 & 7 & 8 & 9 & 10 \\
\hline $\begin{array}{l}\text { Tempo para trocar 1 rolo } \\
\text { de pressão (segundos) }\end{array}$ & 291,26 & 304 & 267,94 & 325,08 & 261,36 & 306,04 & 347,83 & 257,84 & 337,23 & 237,4 \\
\hline \hline $\begin{array}{l}\text { Dados e resultado } \\
\text { conforme a Equação 1 }\end{array}$ & $\mathrm{Z}_{(95 \%)}$ & Desvio padrão (s) & $a$ & \multicolumn{2}{|c|}{$x$} & \multicolumn{3}{|c|}{$N$} \\
\cline { 2 - 10 } & 1,96 & 36,87 segundos & $10 \%$ & 293,60 segundos & 6,06 (arredondamento para 6) \\
\hline Conclusão & $n \geq \boldsymbol{N}$, número de medidas realizadas suficientes \\
\hline
\end{tabular}

Figura 8 - Coleta de dados para a troca de 1 rolo de pressão

Fonte: Elaborado pelos autores

Além disso, conforme a sistemática proposta, após o estudo dos tempos de setup (Estágio preliminar), ocorre a separação e organização do setup interno (Estágio 1). Com isso, dentro das operações analisadas, as atividades "garantir que toda a equipe esteja com os com EPIs", "finalizar a burocracia da última produção" e "solicitar a nova bobina de papel" podem ser feitas enquanto a produção está acontecendo, sem qualquer alteração na atividade em si.

\subsubsection{Construção e Validação do Modelo Conceitual}

Para realizar essa etapa, foi utilizada, inicialmente, a técnica de IDEF-SIM, que mescla técnicas da IDEF0 (representação através de elementos gráficos e textos) e da IDEF3 (que leva em consideração a ordem em que os eventos e atividades ocorrem) (BATEMAN et al., 2013). O modelo está representado no APÊNDICE A. Contudo, durante o desenvolvimento do Modelo Conceitual, constatou-se dificuldade na representação do processo de setup, já que essa técnica tem como foco mostrar as modificações que a entidade sofre durante o processo produtivo e o foco desse estudo é explicar o processo de setup.

Sendo assim, uma segunda técnica foi utilizada: a BPMN (Business Process Modeling and Notation), um padrão de notação visual desenvolvido para modelar processos de negócio. A ferramenta tem como um dos princípios a formação de uma estrutura simples do modelo de processo do negócio, aliada à elementos gráficos de fácil compreensão, possibilitando que um processo complexo seja facilmente representado (FREUND; RÜCKER, 2014). O Apêndice B e o Apêndice C apresentam, respectivamente, os elementos (básicos) que compõem a técnica BPMN e o Modelo Conceitual desenvolvido a partir da técnica BPMN. O modelo final (BPMN) idealizado foi apresentado para a gerência da empresa, que validou o mapeamento do fluxo do processo de setup.

$\mathrm{O}$ processo começa com o setor de Planejamento e Controle da Produção (PCP) informando à equipe de setup qual o formato que será impresso e quando. Quando a linha de produção é parada para setup, o mecânico desliga cada tinteiro e os operadores $(1,2$ e 3$)$ os removem para começar a retirar a unidade de impressão usada. Enquanto isso, o técnico gráfico finaliza os relatórios da última produção e já prepara a inspeção de qualidade para a próxima impressão. Com todos os tinteiros e unidades de impressão retirados, inicia-se a troca dos rolos de pressão, que é supervisionado pelo técnico. Após a troca de todos os rolos de pressão, o mecânico inicia os ajustes no separador e speedflow, enquanto que o técnico, junto com os operadores $(1,2$ e 3), realiza a instalação das novas unidades de impressão e dos tinteiros. Enquanto todas essas operações acontecem, o operador 4 é encarregado de solicitar a nova bobina de papel, posicioná-la e retirar todo o papel que ficou em processo.

Com tudo pronto para iniciar a nova impressão, o técnico gráfico faz o alinhamento da nova bobina na máquina e realiza a primeira puxada de papel. Durante essa puxada, o técnico realiza o acerto e registro das cores, enquanto que o mecânico faz o ajuste fino no separador e speedflow. Após todos esses ajustes, o setup é considerado encerrado e o técnico gráfico informa o setor de PCP. 


\subsection{Etapa 2: Implementação}

Na segunda etapa foram realizados o desenvolvimento, a verificação e a validação do Modelo Computacional.

\subsubsection{Construção e Verificação do Modelo Computacional}

Com os dados coletados e com o Modelo Conceitual validado, iniciou-se a construção do Modelo Computacional no software Promodel. Os elementos utilizados na construção do modelo foram: (i) Locais, (ii) Entidades, (iii) Redes de caminhos, (iv) Recursos, (v) Processos e (vi) Chegadas. O Modelo Computacional construído está representado na Figura 9.

A verificação do modelo ocorreu de duas maneiras. Primeiro foi analisada a sequência de operações e, em seguida, foi verificado, com dados determinísticos, se o tempo total de setup simulado, bem como as operações, eram semelhantes ao processo real. Dessa forma, garantiu-se a verificação do modelo.

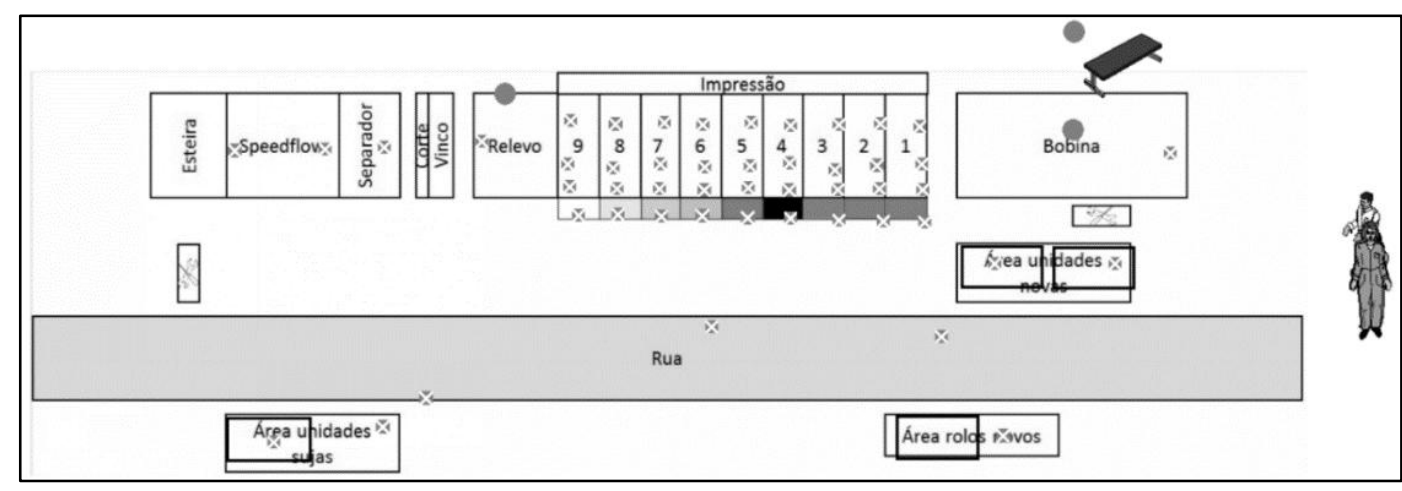

Figura 9 - Modelo Computacional

Fonte: Elaborado pelos autores

\subsubsection{Validação do Modelo Computacional}

Com o modelo verificado, incluiu-se a variabilidade no modelo, com base nos dados coletados. Inicialmente foram feitas 15 replicações do modelo, para gerar uma amostra piloto. A partir dessa amostra foi possível determinar se o número de replicações foi o suficiente [equação (2)], de acordo com a precisão desejada, assim, possibilitando que o modelo seja validado (CHWIF; MEDINA, 2007). Uma replicação representa a simulação de um processo de setup. Este é concluído quando a atividade "Ajuste fino no speedflow - batedores" é finalizada.

$$
n^{*}=n \cdot\left(\frac{h}{h^{*}}\right)^{2}
$$

Sendo, $n^{*}=$ número mínimo de replicações necessárias; $n=$ número de replicações realizadas; $h=$ semi-intervalo de confiança já obtido; $h^{*}=$ semi-intervalo de confiança desejado. Para isso, o $h$ foi calculado conforme a equação (3).

$$
h=t_{n-1,(\alpha / 2)} \cdot\left(\frac{s}{\sqrt{n}}\right)
$$

Onde, $\alpha \Omega$ = nível de significância para o intervalo unicaudal; $\mathrm{t}_{\mathrm{n}-1,(\alpha 2)}=$ distribuição $t$-student , com $n-1$ graus de liberdade; $s=$ desvio padrão das replicações; e $n=$ número de replicações realizadas.Conforme a Figura 10, o número de replicações realizadas foi o suficiente, visto que $n \geq n$. Para o cálculo, buscou-se um semi-intervalo de confiança $\left(h^{*}\right)$ igual a $10 \%$ da média do tempo de 
setup real. Assim, o modelo simulou o setup da empresa com uma diferença média de $3,40 \%$, que o aproxima muito à realidade da empresa, validando, assim, o Modelo Computacional.

\begin{tabular}{|l|c|c|c|c|c|c|c|c|c|c|c|c|c|c|c|}
\hline \multicolumn{1}{|c|}{$\boldsymbol{n}$} & $\mathbf{1}$ & $\mathbf{2}$ & $\mathbf{3}$ & $\mathbf{4}$ & $\mathbf{5}$ & $\mathbf{6}$ & $\mathbf{7}$ & $\mathbf{8}$ & $\mathbf{9}$ & $\mathbf{1 0}$ & $\mathbf{1 1}$ & $\mathbf{1 2}$ & $\mathbf{1 3}$ & $\mathbf{1 4}$ & $\mathbf{1 5}$ \\
\hline $\begin{array}{l}\text { Tempo de setup } \\
\text { (minutos) }\end{array}$ & 239,88 & 240,4 & 139,73 & 255,18 & 253,85 & 251,28 & 249,62 & 240,05 & 243,23 & 251,2 & 134,2 & 249,05 & 250,2 & 234,33 & 246 \\
\hline $\begin{array}{l}\text { Dados e resultado } \\
\text { conforme a Equação 2 e 3 }\end{array}$ & $\mathbf{t}_{\mathbf{1 4 , 0 , 0 5}}$ & Desvio padrão (s) & $\boldsymbol{\alpha}$ & $\boldsymbol{h}$ & \multicolumn{7}{|c|}{$\boldsymbol{n}^{*}$} \\
\hline
\end{tabular}

Figura 10 - Cálculo do número de replicações

Fonte: Elaborado pelos autores

Além disso, o modelo gerou informações quanto a utilização dos funcionários, que ajudaram na definição dos experimentos. O mecânico é o recurso mais utilizado, enquanto que os operadores 1 , 2 e 3 ficam muito tempo ociosos (Figura 11). É importante ressaltar que o tempo ocioso dos operadores se justifica pela limitação de atividades que eles podem exercer, de acordo com as leis trabalhistas.

\begin{tabular}{|l|c|c|c|}
\hline Funcionário & Tempo em operação & Tempo em movimentação & Tempo ocioso \\
\hline Técnico gráfico & $50,50 \%$ & $0,88 \%$ & $48,61 \%$ \\
\hline Mecânico & $73,82 \%$ & $1,57 \%$ & $24,61 \%$ \\
\hline Operador 1 & $14,12 \%$ & $1,48 \%$ & $84,40 \%$ \\
\hline Operador 2 & $13,79 \%$ & $1,49 \%$ & $84,72 \%$ \\
\hline Operador 3 & $13,74 \%$ & $1,30 \%$ & $84,96 \%$ \\
\hline Operador 4 & $59,10 \%$ & $1,29 \%$ & $39,61 \%$ \\
\hline
\end{tabular}

Figura 11 - Ocupação média dos funcionários durante o setup atual Fonte: Elaborado pelos autores

\subsection{Etapa 3: Análise}

Na Etapa 3 foram realizados os experimentos com melhorias no processo analisado e a análise dos resultados obtidos.

\subsubsection{Definição do(s) Experimento(s)}

As melhorias propostas foram definidas com base no Estágio 2 e no Estágio 3 da TRF, propostos por Shingo (2000), além de incorporar a separação e organização do setup interno das atividades.

Para preparar as atividades operacionais com antecedência e converter o setup interno em externo foram definidas: (i) uma atividade de montagem dos "batedores" em paralelo a produção, ou seja, quando a linha de produção parar só há necessidade de troca do sistema montado; (ii) a utilização de gabaritos para reduzir o tempo de ajuste fino; (iii) a troca de componentes no "speedflow" para eliminar a necessidade de trocá-los; e (iv) a identificação de rolos e alocação em locais próximos ao seu uso, para minimizar movimentações dos operadores.

Também foi definida a formação de duas equipes para a área de "impressão", uma formada por dois operadores e outra por um operador e um técnico gráfico. Essas ações visam uma melhor distribuição de tarefas, aumentando o número de operações em paralelo. Ainda no que diz respeito às atividades em paralelo, o mecânico foi alocado para, inicialmente, realizar as operações no "speedflow - batedores" e no "separador", para depois realizar a atividade de alinhamento do papel. A mesma 
estratégia foi empregada na atividade "retirar o papel em processo", onde o operador, após terminar suas atividades, auxiliará o operador 4. O Apêndice D contempla um resumo das mudanças sugeridas.

Nesta etapa foram definidos três cenários. O cenário 1 contempla a inclusão de um mecânico na equipe, sem aplicar melhorias nas operações. Já no cenário 2 é mantida a equipe original, mas com as melhorias nas operações. Por fim, o cenário 3 integra as mudanças propostas nos cenários 1 e 2 .

\subsubsection{Análise dos Resultados das Simulações}

Assim como na validação do Modelo Computacional, todos os cenários tiveram 15 replicações de simulação. A Figura 12 apresenta os resultados dos cenários 1, 2 e 3 em relação ao cenário atual. Pode-se notar que, no Cenário 1, a inclusão de um mecânico na equipe, não trouxe grandes efeitos em relação a redução do tempo de setup.

\begin{tabular}{|c|c|c|c|c|c|}
\hline Funcionário & Indicador & Cenário atual & Cenário 1 & Cenário 2 & Cenário 3 \\
\hline \multirow{3}{*}{$\begin{array}{l}\text { Técnico } \\
\text { gráfico }\end{array}$} & Tempo em operação & $50,50 \%$ & $53,84 \%$ & $59,42 \%$ & $60,54 \%$ \\
\hline & Tempo em movimentação & $0,88 \%$ & $1,02 \%$ & $2,73 \%$ & $2,78 \%$ \\
\hline & Tempo ocioso & $48,61 \%$ & $45,14 \%$ & $37,85 \%$ & $36,68 \%$ \\
\hline \multirow{3}{*}{ Mecânico 1} & Tempo em operação & $73,82 \%$ & $41,52 \%$ & $62,67 \%$ & $52,78 \%$ \\
\hline & Tempo em movimentação & $1,57 \%$ & $0,45 \%$ & $1,07 \%$ & $0,75 \%$ \\
\hline & Tempo ocioso & $24,61 \%$ & $58,03 \%$ & $36,26 \%$ & $46,74 \%$ \\
\hline \multirow{3}{*}{ Mecânico 2} & Tempo em operação & - & $38,54 \%$ & - & $11,06 \%$ \\
\hline & Tempo em movimentação & - & $1,31 \%$ & - & $41,00 \%$ \\
\hline & Tempo ocioso & - & $60,15 \%$ & - & $88,53 \%$ \\
\hline \multirow{3}{*}{ Operador 1} & Tempo em operação & $14,12 \%$ & $17,85 \%$ & $32,96 \%$ & $33,58 \%$ \\
\hline & Tempo em movimentação & $1,48 \%$ & $1,36 \%$ & $1,91 \%$ & $1,95 \%$ \\
\hline & Tempo ocioso & $84,40 \%$ & $80,79 \%$ & $65,13 \%$ & $64,48 \%$ \\
\hline \multirow{3}{*}{ Operador 2} & Tempo em operação & $13,79 \%$ & $17,55 \%$ & $20,53 \%$ & $20,91 \%$ \\
\hline & Tempo em movimentação & $1,49 \%$ & $1,42 \%$ & $1,97 \%$ & $2,00 \%$ \\
\hline & Tempo ocioso & $84,72 \%$ & $81,03 \%$ & $77,50 \%$ & $77,08 \%$ \\
\hline \multirow{3}{*}{ Operador 3} & Tempo em operação & $13,74 \%$ & $17,39 \%$ & $18,34 \%$ & $18,69 \%$ \\
\hline & Tempo em movimentação & $1,30 \%$ & $1,35 \%$ & $1,58 \%$ & $1,61 \%$ \\
\hline & Tempo ocioso & $84,96 \%$ & $81,25 \%$ & $80,08 \%$ & $79,70 \%$ \\
\hline \multirow{4}{*}{ Operador 4} & Tempo em operação & $59,10 \%$ & $54,39 \%$ & $50,08 \%$ & $51,02 \%$ \\
\hline & Tempo em movimentação & $1,29 \%$ & $1,17 \%$ & $0,09 \%$ & $0,09 \%$ \\
\hline & Tempo ocioso & $39,61 \%$ & $44,44 \%$ & $49,84 \%$ & $48,89 \%$ \\
\hline & Diferença no tempo de setup & - & $-1,22 \%$ & $-29,52 \%$ & $-30,82 \%$ \\
\hline
\end{tabular}

Figura 12 - Comparação entre o cenário atual e os cenários simulados Fonte: Elaborado pelos autores

O mecânico adicional ajuda a realizar outras atividades de forma mais rápida, mas o gargalo do processo de setup se mantém. Além disso, o percentual de ociosidade do mecânico aumentou, enquanto que a utilização dos demais funcionários variou pouco. A diferença de tempo de setup ($1,22 \%$ ), observada na Figura 12, está atrelada à variabilidade do processo e não à adição de um mecânico.

Por outro lado, o Cenário 2 trouxe resultados expressivos. As melhorias propostas possibilitaram que mais atividades em paralelo ocorressem. Isso permitiu uma redução (média) do tempo de setup de $29,52 \%$. Além disso, pode-se notar que a utilização dos operadores aumentou e que o tempo de movimentação do mecânico foi reduzido. Por fim, nos resultados do Cenário 3, é possível 
notar que, assim como no Cenário 1, a inclusão de mais um mecânico não gera melhorias significativas, quando comparado com os resultados obtidos no Cenário 2.

Através da simulação dos 3 cenários propostos, foi possível observar o impacto no tempo de setup, bem como na utilização dos funcionários. O cenário atual apresenta um alto tempo de setup, afetando a disponibilidade da linha de produção. As propostas de melhoria foram definidas com base na metodologia da TRF, com as melhorias relacionadas às operações em paralelo (Estágio 3) gerando maior impacto no tempo de setup, pois afetaram em atividades críticas do processo estudado.

Observou-se que o cenário 2 apresenta os melhores resultados, visto que não é necessário modificar o quadro atual de funcionários da empresa, as melhorias afetam o caminho crítico do processo e há uma maior utilização dos recursos disponíveis. Entretanto, devido ao escopo do trabalho, nenhum dos cenários possibilitou avaliar os impactos que as melhorias com a TRF trouxeram no que diz respeito ao mix de produção, nível de estoque, qualidade, custo de fabricação e lead time. A Figura 13 apresenta uma análise dos resultados obtidos neste estudo com os resultados esperados com a implantação da TRF.

\begin{tabular}{|l|c|c|}
\hline \multicolumn{1}{|c|}{ Características } & Efeito Esperado & Efeito no Cenário 2 \\
\hline Setup interno & Redução & Redução \\
\hline Tempo de setup & Redução & Redução \\
\hline Disponibilidade da linha de produção & Aumento & Aumento \\
\hline Capacidade produtiva & Aumento & Aumento \\
\hline Mix de produção & Aumento & N/A \\
\hline Nível de estoque & Redução & N/A \\
\hline Qualidade & Aumento & N/A \\
\hline Custo de fabricação & Redução & N/A \\
\hline Lead Time & Redução & N/A \\
\hline
\end{tabular}

Figura 13 - Comparativo dos efeitos esperados e verificados através da simulação Fonte: Elaborado pelos autores

\section{Considerações finais}

Este trabalho teve como objetivo propor uma sistemática para avaliar as operações de setup, utilizando a simulação computacional como ferramenta de análise de alterações nas operações estudadas e a TRF para reduzir o tempo do processo de setup. Tal objetivo foi alcançado, visto que foi possível aplicar a sistemática proposta, em uma linha de produção de uma empresa gráfica, obtendo resultados que validam a teoria de TRF apresentada na literatura especializada.

Além disso, os objetivos específicos também foram alcançados, já que foi realizado um estudo dos principais autores de cada ferramenta aplicada. Foram utilizados os estágios e técnicas de TRF, propostos por Shingo (2000), para sugerir as melhorias que visam minimizar o tempo de setup e gerar um modelo computacional para experimentação de cenários de melhoria no setup.

A aplicação dos conceitos de TRF possibilitou identificar que algumas tarefas que já ocorriam durante o setup poderiam ser realizadas durante o setup externo, gerando uma redução significativa no tempo de setup. Contudo, vale ressaltar a importância de identificar e atuar no gargalo do processo, caso contrário, as melhorias propostas não surtirão o efeito esperado. Além disso, é importante salientar que, mesmo não atingindo um tempo de setup inferior a 9 minutos e 59 segundos, a implementação dos conceitos da TRF podem trazer melhorias significativas para a empresa, expandindo os ganhos para questões como melhor utilização dos recursos, maior capacidade produtiva e menor nível de estoque, por exemplo.

A simulação computacional auxiliou na visualização da dinâmica do processo estudado, gerando informações importantes sobre a utilização de cada funcionário durante o setup e que 
auxiliaram na definição dos experimentos. Além disso, durante o estudo, foi constatada a importância de buscar diferentes técnicas para o entendimento e a representação do modelo conceitual.

Através dos resultados obtidos nas simulações, verificou-se que as melhorias aplicadas no Cenário 2, trouxeram uma diminuição de $29,52 \%$ no tempo de setup se comparado com o processo atual da empresa, enquanto que o Cenário 1, sem as melhorias e apenas acrescentando um mecânico, trouxe $1,22 \%$ de redução. Já o Cenário 3, trouxe grande redução de tempo de setup, quando comparado com o processo atual da empresa, porém o efeito é devido as melhorias na s operações e não ao mecânico alocado ao processo.

É importante ressaltar que mudanças nos processos sempre geram um impacto e resistência por parte dos envolvidos. Assim, embora as simulações indiquem que é possível obter melhorias satisfatórias, estas não ocorrerão imediatamente após suas implementações e, sim, gradualmente.

Para trabalhos futuros, sugere-se realizar um estudo de viabilidade econômica para a implementação das melhorias propostas, adotando o Cenário 2 como referência. Além disso, é interessante avaliar o impacto que a utilização da TRF terá em outros parâmetros não avaliados neste estudo, como por exemplo, o mix de produção, o nível de estoque, a qualidade, o custo de fabricação e o lead time de produção.

\section{Referências}

ABDULMALEK, F.A.; RAJGOPAL, J. Analyzing the benefits of lean manufacturing and value stream mapping via simulation: A process sector case study. International Journal of Production Economics, v.107, p. 223-236, 2007.

BANKS, J. Principles of simulation. In: BANKS, J. Handbook of Simulation: Principles, Methodology, Advances, Applications and Practice. New York: John Wiley \& Sons, Inc., 1998, 870p.

BATEMAN, R. E.; BOWDEN, R. G.; GOGG, T. J.; HARREL, C. R.; MOTT, J. R. A. Simulação de sistemas: Aprimorando processos de Logística, Serviços e Manufatura. 1 ed. Rio de Janeiro: ELSEVIER, 2013. 161p.

BLACK, J. T. O projeto da fábrica com futuro. Porto Alegre: Bookman, 1998, 288 p.

BRANDI, D.; GIACAGLIA, G.E.O. Aumento da Produtividade em uma Indústria Gráfica de Embalagens por Meio da Redução dos Tempos de Setup de Impressão e Uso de Tecnologias Sustentáveis. Sistemas \& Gestão, v.7, n.4, 2012.

CARLETO, N. A Importância da Simulação Computacional em Projetos de Sistemas na Área de Engenharia Elétrica. In: $2^{\circ}$ CONGRESSO BRASILEIRO DE SISTEMAS, 2, 2006, Ribeirão Preto.

CARNOVALI, F.C.; FILHO, R.P.L.; SANTOS, Y.R.; SILVA, J.E.A.R. Estudo de Aplicação do Método SMED para Redução do Tempo de Setup em Máquinas Injetoras de Termoplásticos com Suporte de Simulação Computacional. In XXXII Encontro Nacional de Engenharia de Produção (ENEGEP), 32, 2012, Bento Gonçalves.

CHWIF, L. Redução de modelos de simulação de eventos discretos na sua concepção: uma abordagem causal. 1999, Dissertação (Doutorado em Engenharia Mecânica) - PPGEM/USP, 1999.

CHWIF, L.; MEDINA, A. C. Modelagem e simulação de eventos discretos: teoria e aplicações. $2^{\mathrm{a}}$ Edição. São Paulo, Editora dos Autores, 2007, 320 p.

ELIAS, S.J.B.; DAGOBERTO NETO, R.F.; DYNA, M.A.S. Aplicação da Troca Rápida de Ferramentas na Indústria Alimentícia. In: XXVIII Encontro Nacional de Engenharia de Produção (ENEGEP), 28, 2008, Rio de Janeiro.

FAGUNDES, P.R.M., Sistemática para Redução do Tempo de Setup na Indústria Moveleira. 2002, Dissertação (Mestrado em Engenharia de Produção) - Faculdade de Engenharia, PPGEP/UFRGS, Porto Alegre, 2002. 
FOGLIATTO, F. S.; FAGUNDES, P.R.M. Troca rápida de ferramentas: proposta metodológica e estudo de caso. Gestão \& Produção, v. 10, n. 2, p. 163-181, 2003.

FREUND, J.; RÜCKER, B. Real-Life BPMN: Using BPMN 2.0 to Analyze, Improve and Automate Processes in Your Company. 2 ed. Camunda, 2014205 p.

HARREL, C. R.; MOTT, J. R. A.; BATEMAN, R. E.; BOWDEN, R. G.; GOGG, T. J. Simulação: otimizando os sistemas. 2 ed. São Paulo: IMAM, 2002.

LAW, A. M.; KELTON, W. D. Simulation Modeling and Analysis. 3 ed. New York: McGraw-Hill, 2000, 760 p.

MAIA, R.A.; IDROGO, A.A.A.; LEITE, M.S.A. O Uso da Troca Rápida de Ferramenta (TRF) para Otimizar as Operações de Setup em uma Indústria do Ramo Calçadista. In XXVIII Encontro Nacional de Engenharia de Produção (ENEGEP), 28, 2008, Rio de Janeiro.

MARTINS, P.G.; LAUGENI, F.P. Administração da Produção. 6 ed. São Paulo: Saraiva, 2002, 445 p.

MCHANEY, R. Computer Simulation: A practical Perspective. 1 ed. California: Academic Press, 1991, $275 \mathrm{p}$.

MIRANDA, R.C.; FERNANDES, B.C.; RIBEIRO, J.R.; MONTEVECHI, A.B.; PINHO, A.F. Avaliação da Operação de Setup em uma Célula de Manufatura de uma Indústria de Autopeças Através da Simulação a Eventos Discretos. Revista Gestão Industrial, v.6, n.3, p. 1-21, 2010.

MONDEN, Y. Toyota Production System: Practical Approach to Production Management. São Paulo: IMAM, 1983, 247 p.

MONTEIRO, A.; MENEZES, J.; MONTEIRO, D.V.C. Troca Rápida de Ferramentas aplicada a uma indústria siderúrgica do Rio de Janeiro: um estudo de caso. In: XII Simpósio de Engenharia de Produção, 12, 2005, Bauru, p. 1-12, 2005.

OLIVEIRA, C.S. Aplicação de técnicas de simulação em projetos de manufatura enxuta. Estudos Tecnológicos, v.4, n.3, p. 204-217, 2008.

OLIVEIRA, J.M. Troca Rápida de Ferramentas com Auxílio de Simulação Computacional Aplicada em Processo de Extrusão de Compostos. Dissertação (Mestrado Engenharia Mecânica) Faculdade de Engenharia, programa de Mestrado Profissional em Engenharia Mecânica/UNITAU, Taubaté, 2013.

OLIVEIRA, M.B. Análise dos impactos da Troca Rápida de Ferramentas em Pequenos Lotes de Fabricação: um estudo de caso. In: XXVIII Encontro Nacional de Engenharia de Produção (ENEGEP), 28, 2008, Rio de Janeiro.

PEREIRA, I.C., Proposta de Sistematização da Simulação para Fabricação em Lotes. 2000, Dissertação (Mestrado em Engenharia de Produção) - PPGEP/UNIFEI, Itajubá, 2000.

PONTES, H.L.J.; CARMO, B.B.T.; CHON, S.Y.; PORTO, A.J.V. Implantação da Troca Rápida de Ferramentas para melhoria do desempenho do setor de empacotamento de uma fábrica de café. In: XIV Simpósio de Engenharia de Produção, 14, 2007, Bauru, p. 1-12, 2007.

RANGEL, D.A.; FREITAS, L.M.; DE ASSIS II, O.R.; DO RÊGO, T.P. Aumento da eficiência produtiva através da redução do tempo de setup: aplicando a troca rápida de ferramentas em uma empresa do setor de bebidas. Pesquisa e Desenvolvimento em Engenharia de Produção, v. 10, n. 1, p. 36-49, 2012.

SARGENT, R.G. Validation and Verification of Simulation Models. In: S. JAIN, R.R. CREASEY, J. HIMMELSPACH, K.P. WHITE, and M. FU (editores). Simulation Conference Proceedings, 43, 2011, Phoenix, p. 183-198, 2011.

SATOLO, E.G.; CALARGE, F.A. Troca Rápida de Ferramentas: estudo de casos em diferentes segmentos industriais. Exacta, v.6, n.2, p. 283-296, 2008. 
SHINGO, S. Sistema de Troca Rápida de Ferramentas. 1 ed. Porto Alegre: Editora Bookman, 2000, $327 \mathrm{p}$.

SOARES, J.P.M.; LEMOS, F.O.; ARAÚJO, C.L.K.; HANSEN, P.B. A contribuição da simulação computacional para a análise sistêmica da reestruturação de layout e otimização de recursos na manufatura celular: estudo de caso em uma célula de uma empresa do ramo automotivo. Produto \& Produção, v.12, n.3, p. 49-68, 2011.

WALPOLE, R.E.; MYERS, R.H., MYERS, S.L.; YE, K. Probability and statistics for engineers and scientists. 9 ed. New York: Pearson, 2012, 791 p.

WILLIAMS, E.J.; ÇELIK, H. Analysis of Conveyor Systems within Automotive Final Assembly. In: MEDEIROS, D. J.; WATSON, E. F.; CARSON, J. S.; MANIVANNAN, M. S. (editores). Simulation Conference Proceedings, 30, 1998, Washington, p. 915-920, 1998.

XAVIER, C.A.R.; CARVALHO, S.M.; FILHO, F.S.P.; SANTOS, M.C. A Melhoria do Setup de uma Empresa de Usinagem: Um Estudo de Caso em Porto Velho, Estado de Rondônia, Brasil.

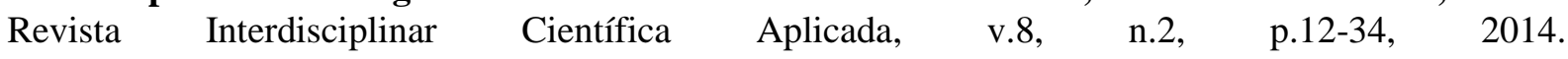




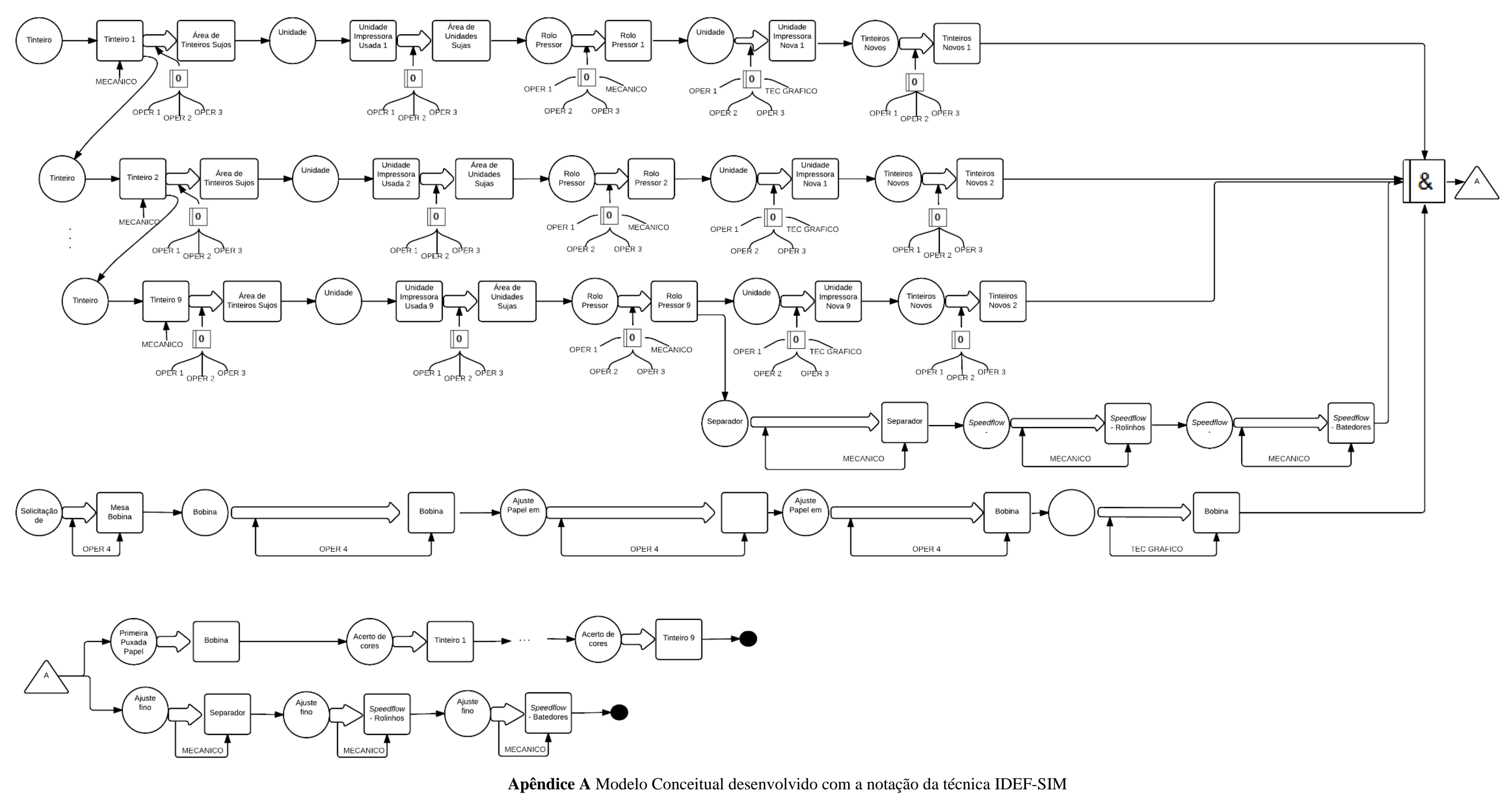


Apêndice B

Elementos (básicos) que compõem a técnica BPMN

\begin{tabular}{|c|c|c|c|}
\hline Elemento & \multicolumn{2}{|l|}{ Símbolo } & Significado \\
\hline \multirow{2}{*}{ Atividade } & & Tarefa & \multirow{2}{*}{$\begin{array}{l}\text { Representa o que deve ser executado em um processo. Pode ser uma tarefa ou } \\
\text { subprocesso. }\end{array}$} \\
\hline & $\boxplus$ & Subprocesso & \\
\hline \multirow{3}{*}{ Evento } & & Início & \multirow{3}{*}{$\begin{array}{l}\text { Ocorre durante um processo e influencia no processo. } \\
\text { Eles ainda podem ser classificados em: mensagem, marcador de tempo, regra, } \\
\text { conector, múltiplo, exceção, compensação e cancelamento. }\end{array}$} \\
\hline & & Intermediário & \\
\hline & & Fim & \\
\hline \multirow{3}{*}{$\begin{array}{l}\text { Gateway } \\
\text { (Filtro de } \\
\text { decisão) }\end{array}$} & & Exlusivo & \multirow{3}{*}{$\begin{array}{l}\text { Regulamenta como o fluxo se relaciona no processo ao convergir ou divergir. } \\
\text { Exclusivo: Segue apenas um dos caminhos de acordo com a informação testada (divisão) ou segue o } \\
\text { fluxo quando um dos caminhos chegar ao gateway (unificação); } \\
\text { Paralelo: Divide o fluxo em caminhos que ocorrerão ao mesmo tempo (divisão) ou o fluxo só } \\
\text { continua quando todas as atividades de entrada forem completadas (unificação); } \\
\text { Inclusivo: Segue um caminho (podendo haver uma combinação) de acordo com a informação } \\
\text { verificada (divisão) ou sincroniza todos os fluxos ativos em um (unificação); }\end{array}$} \\
\hline & & Paralelo & \\
\hline & & Inclusivo & \\
\hline \multirow{3}{*}{ Conectores } & & Direção de sequência & Ilustra a ordem das atividades no processo. \\
\hline & $\diamond \cdots \cdots \cdots$ & Direção da mensagem & Representa o deslocamento de mensagens entre duas entidades. \\
\hline & $\Rightarrow$ & Associação dos elementos & Associa dados, informações e artefatos com objetos do fluxograma. \\
\hline Swimlanes & 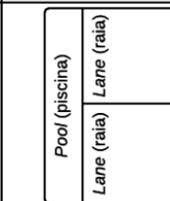 & & $\begin{array}{l}\text { Pool (piscina): representa uma organização. Especifica "quem faz o que", } \\
\text { estabelecendo os eventos e os processos. } \\
\text { Lane (raia): caracterira os participantes envolvidos nas atividades do processo. } \\
\text { Representa um departamento dentro da organização. }\end{array}$ \\
\hline \multirow{3}{*}{ Artefatos } & & Objetos de dados & \multirow{3}{*}{ Exibe mais informações além do fluxograma do processo representado. } \\
\hline & & Agrupamento (Group) & \\
\hline & & Anotações & \\
\hline
\end{tabular}


Apêndice C

Modelo Conceitual desenvolvido com a notação da técnica BPMN

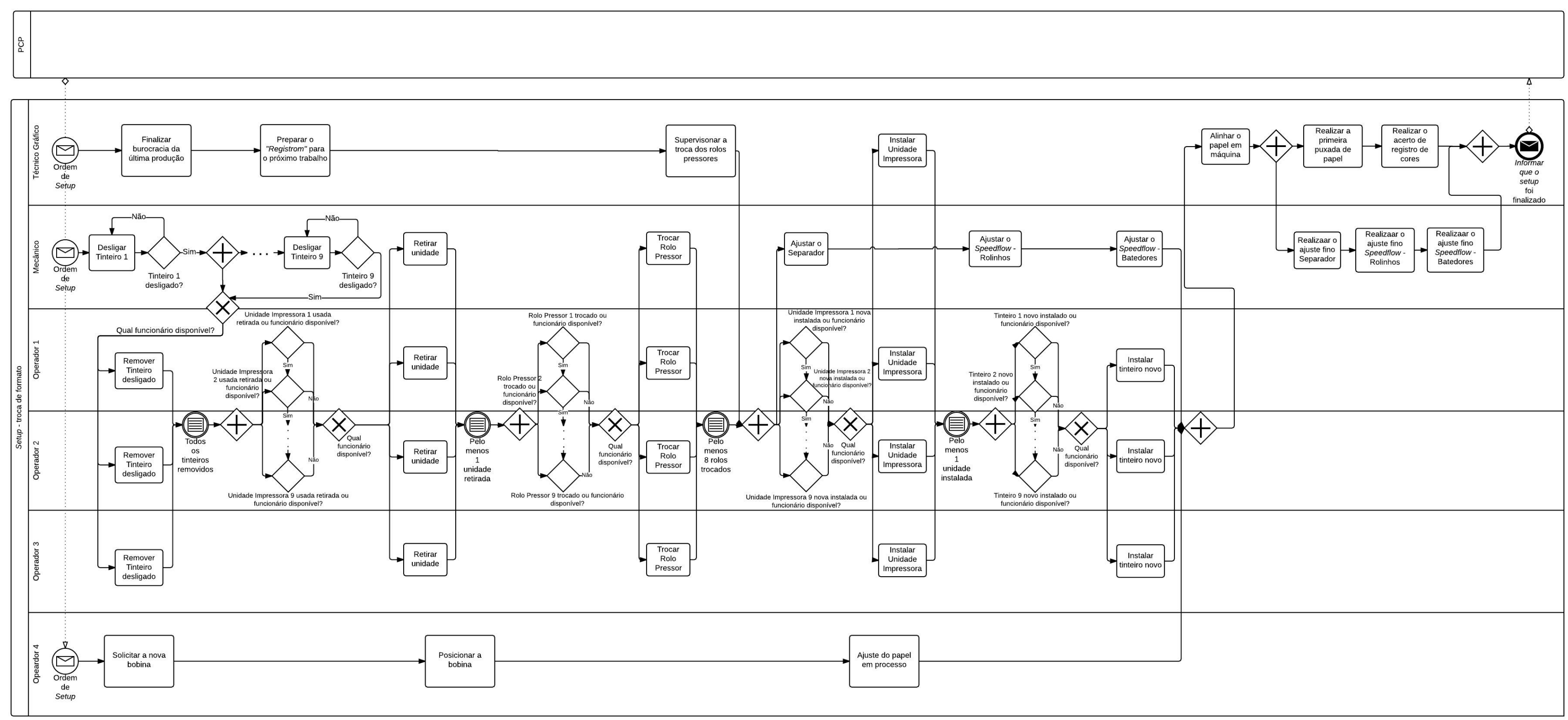




\section{Apêndice D}

\begin{tabular}{|c|c|}
\hline Operação/Atividade & Mudança sugerida \\
\hline $\begin{array}{l}\text { Garantir que toda a equipe esteja com os } \\
\text { com EPIs }\end{array}$ & Realizar durante o setup externo \\
\hline $\begin{array}{l}\text { Finalizar a burocracia da última } \\
\text { produção }\end{array}$ & Realizar durante o setup externo (após a realização do setup) \\
\hline $\begin{array}{l}\text { Preparar o "Registrom" para o próximo } \\
\text { trabalho }\end{array}$ & $\begin{array}{l}\text { Atividade passará a ser realizada pelo mecânico, enquanto o técnico } \\
\text { gráfico faz o alinhamento do papel }\end{array}$ \\
\hline Solicitar a nova bobina de papel & Realizar durante o setup externo \\
\hline Posicionar a nova bobina & - \\
\hline Retirar o papel em processo & $\begin{array}{l}\text { Realizar a atividade em dupla (operador } 4 \text { junto com o operador } 1,2 \\
\text { ou 3): diminui a movimentação do funcionário e reduz o tempo de } \\
\text { atividade. Utilizar walkie talkies para se comunicarem }\end{array}$ \\
\hline Trocar os tinteiros & \multirow{3}{*}{$\begin{array}{l}\text { Incorporar o técnico gráfico na atividade e retirar o mecânico; } \\
\text { Formar duas duplas (técnico e operador 1; operador } 2 \text { e operador 3); } \\
\text { Identificar os rolos de pressão que serão utilizados, bem como } \\
\text { acomodá-los próximos de onde serão instalados. }\end{array}$} \\
\hline Trocar o(s) cinlindro(s) de impressão & \\
\hline Trocar os rolos de pressão & \\
\hline \multicolumn{2}{|l|}{ Ajustar o separador } \\
\hline Ajustar o Speedflow - "rolinhos" & $\begin{array}{l}\text { Eliminar essa operação, substituindo os "rolinhos" por } 3 \text { grandes } \\
\text { rolos, que acomodarão os cartões, após saírem do separador. }\end{array}$ \\
\hline Ajustar o Speedflow - "batedores" & $\begin{array}{l}\text { Adquirir mais uma barra, para montar os "batedores" durante o setup } \\
\text { externo }\end{array}$ \\
\hline Alinhar o papel da nova bobina & $\begin{array}{l}\text { Realizar a atividade em dupla (técnico gráfico e mecânico): diminui } \\
\text { a movimentação do funcionário e reduz o tempo de atividade. } \\
\text { Utilizar walkie talkies para se comunicarem }\end{array}$ \\
\hline Iniciar a primeira puxada do papel & - \\
\hline Realizar o acerto de registro de cores & - \\
\hline $\begin{array}{l}\text { Realizar o ajuste fino no separador e } \\
\text { speedflow ("rolinhos" e "batedores") }\end{array}$ & Adicionar uma régua de referência nas barras \\
\hline
\end{tabular}

Mudanças simuladas 